Tropical Journal of Pharmaceutical Research July 2019; 18 (7): 1539-1546

ISSN: $1596-5996$ (print); 1596-9827 (electronic)

(C) Pharmacotherapy Group, Faculty of Pharmacy, University of Benin, Benin City, 300001 Nigeria.

Available online at http://www.tjpr.org

Original Research Article

http://dx.doi.org/10.4314/tjpr.v18i7.26

\title{
Factors associated with poor glycemic control among type-2 diabetes mellitus patients in Yemen
}

\author{
Sultan AM Saghir ${ }^{1 *}$, Abdullah EA Alhariri², Sameer A Alkubati ${ }^{3}$, Amer A \\ Almiamn ${ }^{4}$, Saleem H Aladaileh ${ }^{1}$, Naelah A Alyousefi ${ }^{5}$ \\ ${ }^{1}$ Department of Medical Analysis, Princess Aisha Bint Al-Hussein College of Nursing and Medical Sciences, Al-Hussein Bin \\ Talal University, Ma an, Jordan, ${ }^{2}$ Preventive Medicine Unit, General Military Hospital, ${ }^{3}$ Department of Nursing, Faculty of \\ Medicine and Health Sciences, Hodeidah University, Hodeidah, Yemen, ${ }^{4}$ Department of Applied Medical Sciences, Community \\ College at Unaizah, Qassim University, Saudi Arabia, ${ }^{5}$ Department of Medicine, Faculty of Medicine, University of Malaya, \\ 50603, Kuala Lumpur, Malaysia
}

*For correspondence: Email: sultan_a1976@yahoo.com; Tel: 00962-781877702

Sent for review: 21 February 2019

Revised accepted: 23 June 2019

\begin{abstract}
Purpose: To determine the status of glycemic control and its associated factors among adult patients with type 2 diabetes mellitus (T2DM) in Hodeidah City, Yemen.

Methods: This cross-sectional study involved T2DM patients attending an outpatient clinic at the Military Hospital in Hodeidah, from January to March 2017. Relevant socio-demographic characteristics, clinical factors and self-management behaviours were recorded in face-to-face interviews. Blood pressure, body weight, and height measurements were also obtained. Glycosylated hemoglobin $(\mathrm{HbA1c})$ and lipid profile were evaluated. Urine samples were also obtained and analysed by albuminuria assay.

Results: Of 246 participants, $73.2 \%$ showed poor glycemic control (HbA1c $\geq 7 \%$ ). Female patients, those aged $\geq 40$ years, the illiterate, and Khat chewers were more likely to have poor glycemic control. Moreover, longer disease duration, insulin administration and albuminuria were significantly associated with poor glycemic control. In contrast, a healthy diet, physical exercise, proper self-monitoring of blood glucose levels and taking medicines as prescribed significantly increased the likelihood of good glycemic control.

Conclusion: A majority of the Yemeni diabetic patients have poor glycemic control. To achieve better awareness, diabetes educational programs that highlight the benefits of self-management are recommended.
\end{abstract}

Keywords: Type 2 diabetes mellitus, Poor glycemic control, Hemoglobin A1c, Diabetics

This is an Open Access article that uses a fund-ing model which does not charge readers or their institutions for access and distributed under the terms of the Creative Commons Attribution License (http://creativecommons.org/licenses/by/4.0) and the Budapest Open Access Initiative (http://www.budapestopenaccessinitiative.org/read), which permit unrestricted use, distribution, and reproduction in any medium, provided the original work is properly credited.

Tropical Journal of Pharmaceutical Research is indexed by Science Citation Index (SciSearch), Scopus, International Pharmaceutical Abstract, Chemical Abstracts, Embase, Index Copernicus, EBSCO, African Index Medicus, JournalSeek, Journal Citation Reports/Science Edition, Directory of Open Access Journals (DOAJ), African Journal Online, Bioline International, Open-J-Gate and Pharmacy Abstracts

\section{INTRODUCTION}

Diabetes mellitus (DM) affects more than 422 million people around the world. By the year 2040, the number of people with diabetes is expected to rise to 642 million, most of who are going to reside in low- or middle-income countries [1]. The numbers of diabetics in the Middle East make for a great concern [2,3]: Yemen (10.4 \%) [4], Saudi Arabia (23.7 \%) [5], 
and Jordan (17\%) [6]. Type 2 diabetes mellitus (T2DM) accounts for $90 \%$ of diabetes cases worldwide [1]. It is considered a major cause of morbidity and mortality especially in low and middle-income countries [7].

The American Diabetes Association (ADA) holds that good glycemic control is essential for the management of DM; and that glycated hemoglobin $(\mathrm{HbA} 1 \mathrm{c})$ is the best indicator for the monitoring of blood glucose levels [8]. HbA1c gives an indication of the average blood glucose levels maintained in the past 3 months [9]. Hence, it is important when estimating the risk of complications associated with the disease [10]. For instance, maintaining $\mathrm{HbA} 1 \mathrm{c}$ levels below or around $7 \%$ (i.e., having good glycemic control) contributes to the reduction, delay and prevention of microvascular and macrovascular complications [8], particularly those involving the eyes, kidneys and nerves [1,3]. Therefore, diabetic patients are advised to maintain the recommended level of $\mathrm{HbA1c}$ to avoid rapid disease progression [10].

Despite the lack of ambiguity about the importance of optimal glycemic control, most of those with diabetes fail to achieve the target level [2]. Poor glycemic control (HbA1c $\geq 7 \%$ ) is rampant in the diabetic populations of Jordan (67\%) [11], and Saudi Arabia (76 \%) [2]. Literatures showed that there are many factors underlie the problem and the better knowledge regarding these factors can enhance health care services and disease management options for patients $[2,6,10]$.

Unfortunately, as far as our knowledge goes, no studies have been conducted in Yemen to explore the factors influencing glycemic control in T2DM. Therefore, this study was intended to determine the factors associated with and the rate of poor glycemic control among T2DM patients in Hodeidah city, Yemen.

\section{METHODS}

\section{Study design and setting}

A cross-sectional study was conducted among T2DM patients who attended the diabetes outpatient clinic at the Military Hospital in Hodeidah, between January and March 2017.

\section{Ethical consideration}

Permission for data collection was obtained from the administration of the intended hospital. The ethical approval was obtained from the research ethics committee at Hodeidah University (Human
Ethics Approval; 166/2-17). Helsinki Declaration guidelines were followed in this study [12]. The participants received illustration of the purpose of the study and they were made aware that their participation in the study would be on voluntary basis and that they were able to withdraw any time. Then, from each participant a written consent was obtained before enrolling in the study.

\section{Participants}

A convenience sample of 246 T2DM patients was selected in this study. Only those aged 18 years or older and have had T2DM for more than 1 year; were included. Newly diagnosed, very sick patients, and those with physical or mental handicaps were excluded from the study. The sample size was calculated using $\mathrm{Eq} \mathrm{1,} \mathrm{and}$ based on a confidence level of $95 \%$ and a margin of error of $5 \%$.

$N=Z^{2} P q / d^{2}$

where $\mathrm{N}$ =sample size, $\mathrm{Z}$ = standard deviation, $\mathrm{P}$ $=$ prevalence of disease, $q=(1-p)$ or percentage of failure which is $100-1=99 \%$, and $d=$ sampling error which is equal to 0.05

\section{Data collection}

Data related to socio-demographic characteristics, clinical factors, and selfmanagement behaviors was collected through face-to-face interviews. Blood pressure, body weight, and height were measured during every interview. Blood samples were collected to assess patients' HbA1c levels and lipid profiles. Urine samples were also collected for albuminuria analyses. Laboratory investigations pertaining to the lipid profile were carried on using a BS-200 Chemistry Analyzer (Mindray Bio-Medical Electronics Co., Ltd , Shenzhen, China), $\mathrm{HbA} 1 \mathrm{c}$ levels were determined using SD A1c Care Analyzer (SD Biosensor Inc, Korea); and urine albumin concentrations were measured using a Uri SCAN Strip (YD Diagnostics Com, Korea).

\section{Measurements and variables}

The socio-demographic characteristics recorded included the patient's sex, age, marital status, residence, educational level, occupation, smoking habits, and khat chewing habits. For the purposes of this study, the educational level referred to the overall years spent in public/private educational organizations as follows: 0 years (illiterate), 1-12 years (school) and $\geq 12$ years (diploma, bachelor, 
postgraduate...etc). A patient was considered to be a smoker if he/she regularly smoked at least one cigarette/daily [9].

The clinical and diabetes-related variables recorded included: the type of current treatment, disease duration, body mass index (BMI), blood pressure, albuminuria and lipid profile levels [(total cholesterol (TC), low-density lipoprotein (LDL), high-density lipoprotein (HDL), and Triglyceride (TG)]. The duration of disease was presented in two categories ( $\leq 7$ and $>7$ years) considering the date of first diagnosis [12]. Body mass index (BMI) values were categorized according to the $\mathrm{WHO}$ classification system into three categories: normal $\left(<25 \mathrm{~kg} / \mathrm{m}^{2}\right)$, overweight $\left(25-29.9 \mathrm{~kg} / \mathrm{m}^{2}\right)$, and obese $(\geq 30$ $\mathrm{kg} / \mathrm{m}^{2}$ ) [13]. Abnormal blood pressure values and lipid profiles were determined relying on the 2013 guidelines of the American Diabetes Association (ADA) [8].

The patients with systolic/diastolic blood pressure levels above $130 / 80 \mathrm{mmHg}$ and those using antihypertensive medications were considered to be hypertensive patients. The definitions of abnormal lipid profile parameters were as follows: $\mathrm{TC} \geq 200 \mathrm{mg} / \mathrm{dl}$ and $\mathrm{HDL}>40$ $\mathrm{mg} / \mathrm{dl}$ in males or $>50 \mathrm{mg} / \mathrm{dl}$ in females; or $\mathrm{LDL} \geq$ $100 \mathrm{mg} / \mathrm{dl}$; or TG $\geq 150 \mathrm{mg} / \mathrm{dl}$. Diabetic dyslipidemia is characterized by the presence of one or more of these serum abnormalities [8].

Data on self-management behaviors were collected to assess patients' adherence to diabetic control measures during the 7 days prior to the interview. These measures included following a proper diet, engaging in physical exercise, taking proper medications, selfmonitoring of blood glucose levels, and practicing proper foot care. A patient was considered to have adequate diabetic control when he/she followed a recommended diet plan for $\geq 3$ days; engaged in physical exercise (walking or exercising) lasting at least $30 \mathrm{~min}$ for $\geq 3$ days; performed self- monitoring of blood glucose levels using a home glucose analysis tool for $\geq 5$ days; and never missed a medication at all [13]. Good glycemic control was defined as having a $\mathrm{HbA1c}$ level < $7 \%$, whereas poor glycemic control was defined as having a $\mathrm{HbA} 1 \mathrm{c}$ level $\geq 7$ $\%$ [8].

\section{Statistical analysis}

The data was organized, verified, and analyzed by using version 21 of the statistical package for social sciences (SSPS) software. Categorical and continuous variables were described as proportions and means (standard deviation, SD), respectively. Pearson's Chi-square and fisher exact test were used to assess the correlation between poor glycemic controls against the recorded variables. All variables showing significant correlations with the univariate analysis were fitted into multiple logistic regression models to determine the independent predictors of all domains. Differences were considered statistically significant at $p \leq 0.05$.

\section{RESULTS}

\section{Socio-demographic characteristics}

A total of 246 participants were recruited in this study. Male participants were $52.4 \%$ of the study population. Half of the participants were in the age category of $40-60$ years (mean $=49.5 \pm$ 11.8 years). The majority of the participants were married (76.8\%), urban residents (69.5\%) and khat chewers (59.3\%). More than one-third (36.2 $\%$ ) were employed as opposed to $17.1 \%$ who were not. Almost one third of the participants (29.3\%) were illiterate and smokers (Table 1).

\section{Clinical and diabetes-related characteristics}

The majority of the participants $(65.0 \%)$ had diabetes for less than 7 years (mean $=7.1 \pm 5.2$ years). Almost two-thirds (67.5\%) were on oral hypoglycemic agents, while a quarter of the participants $(25.2 \%)$ were using insulin. Over a third of the participants $(38.6 \%)$ were overweight $\left(\mathrm{BMI}\right.$ mean $\left.=25.8 \pm 4.9 \mathrm{~kg} / \mathrm{m}^{2}\right)$. The results pertaining to the lipid profile showed that $61.0 \%$ of the participants had dyslipidemia; $23.6 \%$ had high TC levels; $45.1 \%$ had elevated LDL levels; $46.3 \%$ had high TG levels; and $45.0 \%$ of the males and $54.7 \%$ of the females had low HDL levels. Lastly, about one-fifth (20.3 \%) were found to have albuminuria; and less than half $(45.9 \%)$ were hypertensive (Table 2 ).

\section{Poor glycemic control and underlying factors}

The data indicated that poor glycemic control (HbA1c $\geq 7 \%$ ) was rampant among the participants $(73.2 \%)$ and the mean $\mathrm{HbA} 1 \mathrm{c}$ was $8.8 \pm$ 2.2. Multivariate logistic regression revealed that the odds ratio related to poor glycemic control was significantly higher among females $(\mathrm{OR}=1.9,95 \% \mathrm{Cl} 1.1$ - 3.3); those aged 40 years and above $(40-60$ years: $O R=$ $2.4,95 \% \mathrm{Cl} 1.2-4.6$; > 60 years : $\mathrm{OR}=2.6,95$ $\% \mathrm{Cl} 1.2$ - 5.7); the illiterate (OR $=3.2,95 \% \mathrm{Cl}$ $1.3-7.7$ ); and khat chewers (OR= $1.8,95 \% \mathrm{Cl}$ 1.0-3.2). Furthermore, the results of our study showed that poor glycemic control was significant correlated with disease duration ( $\geq 7$ years: $\mathrm{OR}=2.2,95 \% \mathrm{Cl} 1.2-4.2$ ); insulin usage 
$(\mathrm{OR}=2.5,95 \% \mathrm{Cl} 1.1-5.4)$; and the incidence of albuminuria $(\mathrm{OR}=2.7,95 \% \mathrm{Cl} 1.1-6.2$ ) (Table 3).

\section{Self-management behaviors and glycemic control}

The findings of the current study showed that the patients who adhered to a healthy diet as suggested by dietitians $(\mathrm{OR}=0.4,95 \% \mathrm{Cl} 0.2$ $0.7)$; engaged in physical exercise $(\mathrm{OR}=0.5,95$ $\% \mathrm{Cl} 0.2$ - 1.0); self-monitored their blood glucose levels $(\mathrm{OR}=0.5,95 \% \mathrm{Cl} 0.3-0.9)$; and took medicines as prescribed $(\mathrm{OR}=0.6,95 \% \mathrm{Cl}$ 0.3 - 1.0) were less likely to have poor glycemic control (Table 4).

\section{DISCUSSION}

In this study, the majority of the T2DM patients observed $(73.2 \%)$ had poor glycemic control $(\mathrm{HbA} 1 \mathrm{c} \geq 7 \%)$. Similar results have been reported across the Middle East and the Horn of Africa: Jordon (61.1\% and $65.1 \%$ as showcased in [12,14], respectively), Saudi Arabia (50 \%) [2], respectively) and Ethiopia (48.7\%) [15].

The high rate of poor glycemic control observed in this work was not very surprising considering that most of the participants failed to assume adequate self-management behaviors, with 67.9 $\%$ not following a healthy diet, $83.7 \%$ not participating in regular physical exercise, $76.4 \%$ refraining from self-monitoring their blood glucose levels, $77.2 \%$ failing to take proper care of their feet, and $43.9 \%$ skipping some of their medicines. Bad self-management practices have been repeatedly shown to be mendable through health education [16].

However, generally in Yemen, there is a lack of health-education efforts and programs to help patients learn about the risks of diabetes. Consequently, Yemeni diabetic patients have a very poor knowledge and bad attitudes towards disease management, which may be an additional factor contributing to poor glycemic control in the population.

Then again, there are financial limitations in Yemen that make it difficult to provide the necessary healthcare services for patients and prevent patients from accessing such services, which further contributes to the proliferation of inadequate self-management practices. Almost half of the participants in this study $(47.6 \%)$ were found to be unemployed.

Table 1: Socio-demographic characteristics of the patients $(n=246)$

\begin{tabular}{|c|c|c|c|}
\hline Characteristic & Category & No. of patients & $\%$ \\
\hline \multicolumn{4}{|l|}{ Sex: } \\
\hline & Male & 129 & 52.4 \\
\hline & Female & 117 & 47.6 \\
\hline \multicolumn{4}{|c|}{ Age (years), mean (SD) 49.5 (11.8) } \\
\hline & $<40$ & 61 & 24.8 \\
\hline & $40-60$ & 123 & 50.0 \\
\hline & $>60$ & 62 & 25.2 \\
\hline \multicolumn{4}{|l|}{ Marital status } \\
\hline & Single & 21 & 8.5 \\
\hline & Married & 189 & 76.8 \\
\hline & Divorced & 19 & 7.7 \\
\hline & Widowed & 17 & 6.9 \\
\hline \multicolumn{4}{|c|}{ Present residence } \\
\hline & Urban & 171 & 69.5 \\
\hline & Rural & 75 & 30.5 \\
\hline \multicolumn{4}{|c|}{ Education (years) } \\
\hline & 0 & 72 & 29.3 \\
\hline & $1-12$ & 130 & 52.8 \\
\hline & $>12$ & 44 & 17.9 \\
\hline \multicolumn{4}{|l|}{ Occupation } \\
\hline & Employed & 89 & 36.2 \\
\hline & Manual/worker & 40 & 16.3 \\
\hline & House wife & 75 & 30.5 \\
\hline & Unemployed & 42 & 17.1 \\
\hline \multicolumn{4}{|l|}{ Khat chewing } \\
\hline & Khat chewers & 146 & 59.3 \\
\hline & Non-khat chewers & 100 & 40.7 \\
\hline \multicolumn{4}{|l|}{ Smoking } \\
\hline & Smokers & 72 & 29.3 \\
\hline & Non-smokers & 174 & 70.7 \\
\hline
\end{tabular}


Table 2: Clinical and diabetes related variables of the patients $(n=246)$

\begin{tabular}{|c|c|c|c|c|}
\hline Variable & Category & $\mathbf{N}$ & (\%) & Mean (SD) \\
\hline \multirow[t]{3}{*}{ Duration of diabetes (years) } & & & & $7.1(5.1)$ \\
\hline & $<7$ & 160 & 65.0 & \\
\hline & $\geq 7$ & 86 & 35.0 & \\
\hline \multicolumn{5}{|l|}{ Type of treatment } \\
\hline & Diet alone & 18 & 7.3 & \\
\hline & $O H A$ & 166 & 67.5 & \\
\hline & Insulin & 62 & 25.2 & \\
\hline \multirow{4}{*}{ BMI $\left(\mathrm{kg} / \mathrm{m}^{2}\right)$} & & & & $25.8(4.9)$ \\
\hline & Normal & 110 & 44.7 & \\
\hline & Overweight & 95 & 38.6 & \\
\hline & Obese & 41 & 16.7 & \\
\hline \multirow[t]{3}{*}{ Total cholesterol (mg/dl) } & & & & $159.3(51.6)$ \\
\hline & $<200$ & 188 & 76.4 & \\
\hline & $\geq 200$ & 58 & 23.6 & \\
\hline \multicolumn{2}{|l|}{ HDL cholesterol (mg/dl), male } & & & $45.7(10.0)$ \\
\hline & $\geq 40$ & 71 & 55.0 & \\
\hline & $<40$ & 58 & 45.0 & \\
\hline \multirow[t]{3}{*}{ HDL cholesterol (mg/dl), female } & & & & $44.8(11.6)$ \\
\hline & $\geq 50$ & 53 & 45.3 & \\
\hline & $<50$ & 64 & 54.7 & \\
\hline \multirow[t]{3}{*}{ LDL cholesterol (mg/dl) } & & & & $108.1(37.5)$ \\
\hline & $<100$ & 135 & 54.9 & \\
\hline & $\geq 100$ & 111 & 45.1 & \\
\hline \multirow[t]{3}{*}{ Triglycerides (mg/dl) } & & & & $171.6(70.2)$ \\
\hline & $<150$ & 132 & 53.7 & \\
\hline & $\geq 150$ & 114 & 46.3 & \\
\hline \multicolumn{5}{|l|}{ Dyslipidemia } \\
\hline & Yes & 150 & 61.0 & \\
\hline \multirow{2}{*}{\multicolumn{5}{|c|}{ Albuminuria }} \\
\hline & & & & \\
\hline & Positive & 50 & 20.3 & \\
\hline \multirow{3}{*}{ Blood pressure } & Negative & 196 & 79.7 & \\
\hline & & & & \\
\hline & $\begin{array}{l}\text { Normotensive } \\
\text { Hypertensive }\end{array}$ & $\begin{array}{c}133 \\
113\end{array}$ & $\begin{array}{c}54.1 \\
45.9\end{array}$ & \\
\hline
\end{tabular}

Table 3: Logistic regression analysis of socio-demographic and clinical variables associated with poor glycemic control

\begin{tabular}{|c|c|c|c|c|}
\hline Variable & Category & $\begin{array}{l}\text { Poor glycemic } \\
\text { control, N (\%) }\end{array}$ & OR $(95 \% \mathrm{Cl})$ & $P$-value \\
\hline \multirow[t]{2}{*}{ Sex } & Male & $87(67.4)$ & 1.0 & \\
\hline & Female & $93(79.5)$ & $1.9(1.1-3.3)$ & $<0.05$ \\
\hline \multirow{3}{*}{ Age (years) } & $<40$ & $36(59.0)$ & 1.0 & \\
\hline & $40-60$ & $96(77.4)$ & $2.4(1.2-4.6)$ & $<0.01$ \\
\hline & $>60$ & $48(78.7)$ & $2.6(1.2-5.7)$ & 0.021 \\
\hline \multirow[t]{3}{*}{ Education (years) } & 0 & $61(84.7)$ & $3.2(1.3-7.7)$ & $<0.01$ \\
\hline & $1-12$ & $91(70.0)$ & $1.3(0.7-2.7)$ & $>0.05$ \\
\hline & $>12$ & $28(63.6)$ & 1.0 & \\
\hline \multicolumn{4}{|l|}{ Khat chewing } & \\
\hline & Khat chewers & $114(78.1)$ & $1.8(1.0-3.2)$ & $<0.05$ \\
\hline \multicolumn{5}{|c|}{ Duration of diabetes (years) } \\
\hline & $\begin{array}{l}<7 \\
\geq 7\end{array}$ & $\begin{array}{l}109(68.1) \\
71(82.6)\end{array}$ & $\begin{array}{c}1.0 \\
22(12-42)\end{array}$ & $<005$ \\
\hline \multicolumn{5}{|l|}{ Type of treatment } \\
\hline & $O H A$ & $117(70.5)$ & 1.0 & \\
\hline \multirow{3}{*}{ Albuminuria } & Insulin & $53(85.5)$ & $2.5(1.1-5.4)$ & $<0.05$ \\
\hline & Positive & $43(86.0)$ & $2.7(1.1-6.2)$ & $<0.05$ \\
\hline & Negative & $137(69.9)$ & 1.0 & \\
\hline
\end{tabular}


Table 4: Association between self-management behavior and poor glycemic control

\begin{tabular}{|c|c|c|c|c|}
\hline Variable & $\mathbf{N}(\%)$ & $\begin{array}{l}\text { Poor glycemic } \\
\text { control, N (\%) }\end{array}$ & OR $(95 \% \mathrm{Cl})$ & $P$-value \\
\hline Follow a healthy diet & & & & $<0.001$ \\
\hline Adequate & $79(32.1)$ & $47(59.5)$ & $0.4(0.2-0.7)$ & \\
\hline Inadequate & 167(67.9) & $133(79.6)$ & 1.0 & \\
\hline Engaging in physical exercise & & & & $<0.05^{\star}$ \\
\hline Yes & $40(16.3)$ & $24(60.0)$ & $0.5(0.2-1.0)$ & \\
\hline No & $206(83.7)$ & $156(75.7)$ & 1.0 & \\
\hline Self-monitoring blood glucose & & & & $<0.05^{\circ}$ \\
\hline Yes & $58(23.6)$ & $36(62.1)$ & $0.5(0.3-0.9)$ & \\
\hline No & $188(76.4)$ & $144(76.6)$ & 1.0 & \\
\hline Adherence to medication & & & & $<0.05^{\pi}$ \\
\hline Highly adherent & $138(56.1)$ & $94(68.1)$ & $0.6(0.3-1.0)$ & \\
\hline $\begin{array}{l}\text { Non adherent } \\
\text { Foot care }\end{array}$ & $108(43.9)$ & $86(79.6)$ & 1.0 & \\
\hline Yes & $56(22.8)$ & $37(66.1)$ & $0.7(0.4-1.4)$ & 0.307 \\
\hline No & $190(77.2)$ & $143(75.3)$ & 1.0 & \\
\hline
\end{tabular}

It goes without saying that one's income has a great impact on the type of diet he/she consumes. Thus, the critical economical situation and the absence of facilities and good environment will have strong effects on his/her ability to perform physical exercise, adhere to a medication regimen, and continuously monitor his/her blood glucose levels.

In agreement with other studies $[9,17]$, the present study revealed that females with diabetes were more likely to have poor glycemic control than male patients. Females were shown to be more prone to neglect illnesses as compared with males [18]. Moreover, in some parts of the Yemeni community, women might not have complete freedom to dictate the family's diet, exercise outside, acquire medicines inperson and/or commit to monitoring their glucose levels regularly.

In addition, Arabic women usually have to attend to the needs of all family members, which can be taxing and negatively affect their ability to pursue the self-management targets in diabetes [19]. In the present work, older diabetic patients were found to be prone to have poor glycemic control. However, the evidence pertaining to age and its impact on glycemic control has been conflicting. While some reports agree with our findings $[2,20]$, others do not $[13,19]$. Older patients normally have low medication adherence rates as they are more likely to have other chronic diseases or age-related physical and/or mental problems [21,22].

Besides, the classic symptoms of hyperglycemia tend to decrease or disappear in old age due to physiological changes associated with aging and complications arising from other co-morbidities [22]. According to West and Goldberg [23], mean knowledge scores decrease in diabetic patients by $3.0 \%$ every 10 years. Trying to explain why self-management practices and medication adherence rates worsened as age progressed Huang and Davis cited a number of factors, including functional restriction, cognitive impairment, social isolation, diminished health literacy, and financial struggle [24].

The results of the present study indicated that illiterate patients were at greater risk of having poor glycemic control when compared to those having a high level of education. This finding is consistent with other studies $[2,16,23]$. The lack of formal education seems to contribute to poor glycemic control in diabetic patients. This may be due to illiteracy leading to a low level of knowledge regarding disease management, which may result in bad self-management practices [24]. A high level of education, on the other hand, can allow a patient to acquire special skills related to problem-solving and may enhance his/her ability to cope with the disease, manage it and better control his/her_blood glucose levels [2]. The present study revealed that the diabetic patients who chewed Khat were more likely to have poor glycemic control which is compatible with the findings of Al-Sharafi and Gunaid [24]. The researchers argued that poor glycemic control was more common among such patients because chewing khat was a costly habit that may not leave enough money for a person to seek medical assistance.

The results obtained in this work in relation to diabetes-related factors were consistent with other studies $[15,16]$ as longer duration of diabetes had previously been shown to be significantly associated with poor glycemic control. One explanation for this result is that, over time, diabetic patients become exhausted and stop caring about uncontrolled glucose levels or develop a lack of interest in pursuing 
self-management behaviors [15]. Besides, eventually over time, pancreatic $\beta$-cells become unable to secret adequate amounts of insulin [9].

This is due to the fact that diabetic patients treated with insulin generally present with more severe illnesses that required the use of additional drugs to lower the risk of complications. In the present work, albuminuria was found to be significantly associated with poor glycemic control. These findings are in line with those previously reported as the cited report showed nephropathy, a common co-morbidity in T2DM patients to be significantly associated with poor glycemic control in the diabetic population there [22].

This study revealed a significant negative relationship between patient's adherence to selfmanagement activities and poor glycemic control. These findings are similar to previous studies regarding to glycemic control and the beneficial impact of a healthy diet, regular physical exercise [18], self-monitoring of blood glucose levels, and self-administration of medicines as prescribed [19]. An unhealthy diet can lead to body weight gain and obesity, both of which are considered risk factors of poor glycemic control. Increased fat mass and visceral adiposity in obesity may lead to insulin resistance and decreased insulin sensitivity. Hence, regular physical exercise offers many benefits in terms of achieving better management of diabetes as it promotes body weight loss through fat breakdown; reduces blood glucose levels; and enhances the lipid profile [25]. Patients who adequately adhere to self-monitoring practices for 6 to 12 months have recently been shown to be able to achieve a reduction in $\mathrm{HbA} 1 \mathrm{c}$ levels exceeding $1 \%$ [1]. In addition, proper adherence to medications played a major role in achieving good glycemic control in patients subjected to extra intervention efforts in a single year [19]. Consequently, diabetic patients should be encouraged to take their medications at the prescribed intervals.

\section{Limitation of the study}

Some limitations in this study include small sample size as well as all the participants were from the same city (Hodeidah). Thus, this study may not reflect the real situation in the country (Yemen).

\section{CONCLUSION}

The data showcased in the present study reveal a problem with poor glycemic control in a high proportion of type $2 \mathrm{DM}$ patients in Yemen.
Several social, clinical and behavioral factors underlie the problem. Health professionals and decision makers should direct their efforts and interventions towards the empowerment of patients by providing appropriate educational sources that highlight the benefits of selfmanagement in the context of disease treatment, control, and elimination of risk factors.

\section{DECLARATIONS}

\section{Acknowledgement}

The authors would like to thank all the laboratory staff at the Military Hospital in Hodeidah for their assistance with the collection of samples and laboratory investigations. Many thanks also go to Dr. Ashraf Said at the Diabetic Clinic for being very cooperative throughout this study.

\section{Competing interest}

Authors declare that no conflict of interest is associated with this work.

\section{Contribution of authors}

We declare that this work was done by the authors named in this article and all liabilities pertaining to claims relating to the content of this article will be borne by the authors. Sultan AMS, Abdullah EAA and Saleem AA conceived and designed the experiments, Sultan AMS, Amer AA and Abdullah EAA performed the experiments, Sameer HA, Omar YAA and Naelah AA analyzed the data and write the first draft, Abdullah EAA, Sultan AMS and Naelah AA review and edit the manuscript. All authors read and approved the final manuscript.

\section{Open Access}

This is an Open Access article that uses a funding model which does not charge readers or their institutions for access and distributed under the terms of the Creative Commons Attribution License (http://creativecommons.org/licenses/by/ 4.0) and the Budapest Open Access Initiative (http://www.budapestopenaccessinitiative.org/rea d), which permit unrestricted use, distribution, and reproduction in any medium, provided the original work is properly credited.

\section{REFERENCES}

1. Jaacks $L M$, Siegel KR, Gujral UP, Narayan KM. Type 2 diabetes: A 21st century epidemic. Best Pract Res Clin Endocrinol Metab 2016; 30(3): 331-343. 
2. Almutairi MA, Said SM, Zainuddin H. Predictors of Poor Glycemic Control among Type two Diabetic Patients. Am J Med Sci 2013; 3(2): 17-21.

3. Venugopal $S$, Kunju $R$, Al Harthy $S$, Al Zadjali $N$. Hemoglobin A1c in Muscat, Oman - A 3 year study. Oman Med J 2008; 23(3): 170-172.

4. Gunaid AA, Assabri AM. Prevalence of type 2 diabetes and other cardiovascular risk factors in a semirural area in Yemen. East Mediterr Health J 2008; 14(1): 42-56.

5. Al-Nozha MM, Al-Maatouq MA, Al-Mazrou YY, Al-Harthi SS, Arafah MR, Khalil MZ. Diabetes mellitus in Saudi Arabia. Saudi Med J 2004; 25(11): 1603-1610.

6. Ajlouni K, Khader YS, Batieha A, Ajlouni H, El-Khateeb $M$. An increase in prevalence of diabetes mellitus in Jordan over 10 years. J Diabetes Complications 2008 1; 22(5): 317-324.

7. Mathers $C D$, Loncar $D$. Projections of global mortality and burden of disease from 2002 to 2030. PLoS Med 2006;3(11):e442.2008; 22(5): 317-324.

8. American Diabetes A. Standards of medical care in diabetes-2015 abridged for primary care providers. Clin Diabetes 2015; 33(2): 97-111.

9. Adham M, Froelicher ES, Batieha A, Ajlouni K. Glycaemic control and its associated factors in type 2 diabetic patients in Amman, Jordan. East Mediterr Health $J$ 2010; 16(7): 732-739.

10. Al-Khawaldeh OA, Al-Hassan MA, Froelicher ES. Selfefficacy, self-management, and glycemic control in adults with type 2 diabetes mellitus. J Diabetes Complications 2012; 26(1): 10-16.

11. Khattab M KY, Al-Khawaldeh A, Ajlouni K. Factors associated with poor glycemic control among patients with type 2 diabetes. J Diabetes Complications 2010; (24): 84-89.

12. Sulaiman AM, Saghir SA, Al-Hassan FM, Yusoff NM, Zaki AH. Molecular Characterization of Glucose-6Phosphate Dehydrogenase Deficiency in a University Community in Malaysia. Trop J Pharm Res 2013; 12(3), 363-367.

13. WHO G. Global Report on Diabetes, 2016. Available from: http://wwwwhoint/diabetes/global-report/en/. 2016.

14. Hammad S. Darawad M. EH, and Waddah DEMEH. Predictors of Glycated Hemoglobin among Jordanian Diabetic Patients. Iran J Public Health 2015; 44(11): 1482-1491.
15. Eticha TM, Gebretsadik H, Kahsay G, Ali D, Rajeshwar Y. Factors Associated with Poor Glycemic Control in Type 2 Diabetic Patients Investigated at Ayder Referral Hospital, Mekelle, Ethiopia. ljppr Human 2016; 6(3): 160-171.

16. Babelgaith SD, Baidi M A-AM, Alfadly S, Wajid S. Effect of Health Care Professionals' Continuing Education Programme on Diabetic Patients' Outcomes in Mukalla City, Yemen. Trop J Pharm Res 2015; 14(2): 303-309.

17. Kautzky-Willer A, Kamyar MR, Gerhat $D$, Handisurya A, Stemer $G$, Hudson $S$, Luger A, Lemmens-Gruber $R$. Sex-specific differences in metabolic control, cardiovascular risk, and interventions in patients with type 2 diabetes mellitus. Gend Med 2010; 7(6): 571-583.

18. Sanal TS, Nair NS aAP. Factors associated with poor control of type 2 diabetes mellitus: A systematic review and Meta analysis. J Diabetol 2011; 3: 1-10.

19. Al-Rowais NA. Glycemic control in diabetic patients in King Khalid University Hospital (KKUH) - Riyadh - Saudi Arabia. Saudi Pharm J 2014; 22(3): 203-206.

20. Mahfouz EM, Awadalla HI. Compliance to diabetes selfmanagement in rural El-Mina, Egypt. Cent Eur J Public Health 2011; 19(1): 35-41.

21. Mulhem E, Lick D, Varughese J, Barton E, Ripley $T$, Haveman J. Adherence to medications after hospital discharge in the elderly. Int J Family Med 2013; 2013: 901845.

22. DP. P, De Silva RE, WLP. Knowledge of diabetes among type 2 diabetes patients attending a primary health care clinic in Sri Lanka. East Mediterr Health J 2013; 19(7): 644-648.

23. Huang ES, Davis AM. Glycemic Control in Older Adults With Diabetes Mellitus. JAMA 2015; 314(14): 15091510.

24. Al-Sharafi BA, Gunaid AA. Effect of Habitual Khat Chewing on Glycemic Control, Body Mass Index, and Age at Diagnosis of Diabetes in Patients with Type 2 Diabetes Mellitus in Yemen. Clin Med Insights Endocrinol Diabetes 2015; 8: 47-53.

25. Al Omari M, Khader $Y D A$, Al-Akour $N$, Khassawneh AH, Al-Ashker E, Al-Shdifat A. Glycaemic control among patients with type 2 diabetes mellitus treated in primary care setting in Jordan. Primary Care Diabetes 2009; 3(3): 173-179. 